University of Rhode Island

DigitalCommons@URI

Open Access Master's Theses

1975

\title{
The Relationship Between Creativity and Play Behavior of Four- Year-Olds in the Nursery School Settings
}

Peggy Ann Simmons

University of Rhode Island

Follow this and additional works at: https://digitalcommons.uri.edu/theses

\section{Recommended Citation}

Simmons, Peggy Ann, "The Relationship Between Creativity and Play Behavior of Four-Year-Olds in the Nursery School Settings" (1975). Open Access Master's Theses. Paper 1707.

https://digitalcommons.uri.edu/theses/1707

This Thesis is brought to you for free and open access by DigitalCommons@URI. It has been accepted for inclusion in Open Access Master's Theses by an authorized administrator of DigitalCommons@URI. For more information, please contact digitalcommons-group@uri.edu. 
THE RELATIONSHIP BETWEEN CREATIVITY AND PLAY BEHAVIOR OF FOUR-YEAR-OLDS IN

THE NURSERY SCHOOL SETTING

BY

PEGGY SIMMONS

A THESIS SUBMTTTED IN PARTIAL FULFILLMENT OF THE REQUIREMENTS FOR THE DEGREE OF

MASTER OF SCIENCE

IN

CHILD DEVELOPMENT AND

FAMILY RELATIONS

UNIVERSITY OF RHODE ISLAND

1975 


\begin{abstract}
Seventeen high creative and sixteen low creative children (as assessed by the Wallach and Kogan (1965) verbal creativity tasks) were observed during free play in the nursery school in order to test the hypothesis that high and low creative children differ in their free play preferences. Continuously available free play activities were observed in the nursery school and each subject's participation in these activities was recorded. Each subject's play preferences were determined and an analyses of the relationship between creativity scores and play preferences failed to support the hypothesis that high and low creatives differ in play preferences. Sex and age differences on creativity scores and play preferences were investigated and the results were not statisticaliy significant.
\end{abstract}




\section{ACKNOWLEDGEMENTS}

I would like to express my gratitude to those persons who contributed so much to this study.

Dr. George Fitzelle has been extremely helpful to me. His sensitivity to my problems and his valuable contributions to the writing of the thesis were exceptional and beyond the duties expected of a major professor.

I would also like to thank Dr. Gwenneth Rae. She provided insights which immeasurably added to the meaningfulness of the thesis:

In addition, Dr. Domonique Valentino, who served as chairman of my thesis defense, helped to make the defense a valuable learning experience for me.

I would also like to thank Drs. Mollie and Russel Smart and Dr. Henry Biller. The Smarts helped me to begin research in a difficult area of study. Dr. Biller, who served on my thesis committee, was largely responsible for my interest in the area of creativity.

The people at the U.R.I. Child Development Center were extremely cooperative and without their help this study would not have been possible. I would like to thank Dr. Helen Greene, Ms. Rosemary Kohut, and Mrs. Lucille Field for their support of my study. Mrs. Ann D. Kennet and Ms. Sharon Brown were also very helpful. Ms. Margaret Woodward 
and Ms. Debbie Clark, graduate assistants at the Center, were also important in allowing me to complete my research at the nursery school. I would also like to thank the parents and children at the nursery school for their participation in this study.

Finally, I would like to thank my husband, Jim. In addition to the reinforcement he gave me for my thesis writing activity, his experimental and statistical expertise were invaluable. 


\section{TABLE OF CONTENTS}

CHAPTER

Page

I. INTRODUCTION . . . . . . ........ 1

II. REVIEW OF THE LITERATURE. . . . . . . . . . 4

Three Theoretical Approaches to Creativity. 6

A Psychoanalytical Approach . . . . . 6

A "Self-Actualizing" Approach . . . . . 8

Associative Approaches. . . . . . . 11

Maltzman. . . . . . . . . . . 12

Mednick . . . . . . . . . . 13

Creativity Tests... . . . . . . 16

The Guilford Tests. . . .. . . . 16

The Torrance Tests. . . . . . . 23

The Wallach and Kogan Tests... . . . 25

Creativity and Play Behavior. . . . . . 29

III. METHODOLOGY . . . . . . . . . . . . 38

Sample. . . . . . . . . . . 39

Materials............ . . 40

Procedure . . . . . . . . . . 41

IV. RESULTS AND DISCUSSION. . . . . . . . . 43

Results . . . . . . . . . . . 43

Discussion. . . . . . . . . . . 59

V. SUMMARY . . . . . . . . . . . . 63

VI. SUGGESTIONS FOR FUTURE RESEARCH . . . . . . . 65

VII. REFERENCES. . . . . . . . . . . . . 67

APPENDIX A. Examples of Nove1 Activities . . . 71 


\section{LIST OF TABLES}

Table

Page

I Most Preferred Activity. . . . . . . . . 44

2 Activity 1 Versus Activities Other Than 1 . 45

3 Activity 2 Versus Activities other Than 2 . : 46

4 Activity 10 Versus Activities Other than 10. . 49

5 Most Preferred Activity (Omitting Activity 10) 50

6 Activity 1 Versus Activities Other Than 1

(Omitting Activity 10) . . . . . . . 52

7 Activity 2 Versus Activities other Than 2

(Omitting Activity 10) . . . . . . . 53

8 Sex Differences on Creativity Scores . . . . 54

9 Sex Differences in Preferred Activity

Analyzed According to the Fisher Exact

Probability Test . . . . . . . . 55

10 Age Differences on Creativity Scores . . . . 56

11 Age Differences on Preferred Activity. . . . 57 
LIST OF FIGURES

Figure

Page

1 High and Low Creativity for Males and

Females and Preferred Activity. . . . . 


\section{INTRODUCTION}

Interest in the study of the creative process as distinct from a general intelligence dimension has increased steadily since J. P. Guilford (1950) began his research based on the premise that "we must look well beyond the boundaries of IQ if we are to fathom the domain of creativity," (p. 448). Guilford directed his attention to measures that are not usually thought to be involved in tests of intelligence (Stein, 1968). Since Guilford's beginning, researchers in the area of creativity have continued to identify specific abilities which contribute to the creative process and to attempt to construct tests which measure these abilities.

Once creativity was seen as measurable and distinct from general intelligence, researchers began to investigate variables which might correlate with creativity. Their interest has been in variables which might differentiate the person who possesses those abilities associated with creativity from the person who does not possess them or who possesses them to a lesser degree.

There is evidence in the creativity literature that interests and achievements of gifted adults are congruent with interests they showed as children. For example, Mackinnon (1962) has suggested that "most students with 
creative potential have personality structures congruent with, though possibly less sharply delineated than, those of mature creatives," (p. 491).

Revenna Helson (1965) explored the relationship of childhood interest clusters in women to adult creativity. She found evidence of a positive relationship between tomboy interests in childhood and adult creativity. She further found that pleasure from artistic and imaginary activity in childhood was associated with adult indexes of creativity. Finally, social interests in childhood were found to be negatively associated with creativity. Each of these associations was significant beyond the .05 level.

Wallach and Kogan (1965) were interested in classroom behaviors and how they are related to creativity and intelligence. Observations of classroom behaviors were made and subjects in the fifth grade were rated along eight dimensions: attention-seeking; hesitant and subdued; confidence and assurance; sought as a companion; seeks companionship; deprecates own work; concentration on school work; and, interests in school work. Comparisons between boys and girls in the study revealed that intelligence accounted for variations in the observed behaviors for boys, while intelligence, creativity, and the interaction of these two modes of thinking were responsible for differences among the girls.

Most of the research in the area of creativity has 
been directed at older subjects. This has been due primarily to the lack of reliable measures of creativity in young children. With the appearance of the Wallach and Kogan procedures (1965), and their modification by Ward (1968), the study of creativity in young children became possible. Even so, a gap remains in the literature on creativity in preschool children, particularly in the nursery school setting. The present study will attempt to begin closing this gap. Also, although studies in this area have dealt with such variables as home environment (MacKinnon, 1962; Dreyer and Wells; 1966) and other biographical correlates of creativity (Anastasi and Schaefer, 1969), few studies have investigated behavioral variables and their relationship to creativity test scores. In the present study an attempt will be made to explore play behavior in the nursery school environment and its relationship to creativity. 


\section{REVIEW OF THE LITERATURE}

In order to discuss the area of creativity it is first necessary to get an idea of how present views of the creative process evolved and an idea of why the study of creativity is important.

The concept of creativity has been considered for centuries, first as a gift from the gods, or an ability which was due to divine inspiration. It is easy to understand why such a "sacred" area as creativity has only recently been considered to be an area fit for scientific investigation. In fact, it has taken world-shaking events to force an emphasis on creativity as a part of the intellect, a way of thinking, as opposed to a mysterious ability beyond understanding. The most dramatic of these events were the atomic bomb and Sputnik (Razik, 1967). The atomic bomb dramatized the power of science and technology to alter the world.

For Americans, Sputnik catalyzed the realization that further life and development would depend on having many creative persons at work in a constant effort to surpass present accomplishments (Razik, 1967).

In addition to these dramatic reasons for the development of creative potential, an equally compeling reason can be seen in the need for creative control of technolog- 
ical products. As can be seen from the current situation in industrial nations, it is not enough to produce higher levels of technology; the quality of 1 ife depends as much on creative planning for the use of these products as on their production. Technological advances have proceeded at a faster pace than has the ability to successfully accommodate them. Air pollution, the depletion of energy sources, and the problems of large cities are only a few illustrations of this lack of creative planning.

Thus, through necessity, the basic concept of creativity has changed from "something heretofore soft and sentimental to something hard and realistic," (Bazik, 1967, p. 302).

To illustrate this change, three theoretical opinions have been chosen for brief description: a psychoanalytical approach; a "self-actualizing" approach; and two associative approaches to creativity.

In addition, since psychometric studies have made significant contributions to the understanding of creative potential, the research of Guilford, Torrance, and Wallach and Kogan will be presented. The work of these investigators has been important in distinguishing creativity from the area of general intelligence. Also, they have been largely responsible for the emergence of creativity as an area to be studied along with other modes of thinking. Finally, a review of current research relevant to the present study will follow. 
Three Theoretical Approaches to Creativity

\section{A Psychoanalytical Approach to Creativity}

In summarizing Freud's view of creativity, Storr (1972) stated that "Psychoanalysis neither distinguishes between bad art and good; nor, more importantly, between a work of art and a neurotic symptom," (p. 3). This cryptic statement expresses the essence of the psychoanalytic approach. Psychoanalysis has viewed creativity as a mode of expressing "the wish-fulfilling phantasies of the dissatisfied," as a means of "defense against schizoid and depressive states," and as a reflection of a "compulsive need to order and control" (Storr, 1972). Although the predominant view of creativity expressed by Freud was negative, he did express some ambivalence about the area. Storr (1972) points out that on one hand, Freud described the artist as an introvert oppressed by instinctual needs; unable to satisfy these needs, the artist "turns away from reality and transfers all his interest, and his libido, too, to the wishful constructions of his life of phantasy, whence the path might lead to neurosis," (p. 2). On the other hand, however, creative writers are described by Freud as "valuable allies and their evidence is to be praised highly, for they are apt to know a whole host of things between heaven and earth of which our philosophy has not yet let us dream. In their knowledge of the mind they are far in advance of us everyday people, for they 
draw upon sources which we have not yet opened up for science," (p. 3, Storr, 1972). Primarily, however, psychoanalysis presents the creative process as a pathological outlet for individuals who are unable to function on a reality-based plane. Creativity is placed in the context of such concepts as sublimation of sexuality, and retreat from reality into neurotic phantasy. An interesting and extreme example of this interpretation was presented by Storr (1972) in a description of Humberto Nagera's study of Van Gogh. Nagera suggests that "Van Gogh made an unconscious equation between painting and masturbation," (p. 8). Nagera further states that "painting (for Van Gogh) is an attempt at sublimation of his masturbation conflicts and sexuality generally, and at the same time a substitute and a symbol for them," (p. 8, storr, 1972 ).

It should be pointed out that psychoanalytic conclusions about creativity were primarily drawn from the finished products of reportedly creative individuals. Although Freud made many statements concerning the motives and drives behind the creation of these finished products, he seldom speculated as to the creative processes involved in their creation. In his essay, "Creative Writers and Day Dreaming," (Vernon, 1970) Freud did attempt to describe this process to some extent. In this essay, Freud compared the creative writer to a child at play: "The creative writer does the same as the child at play. He 
creates a world of phantasy which he takes very seriously that is, which he invests with large amounts of emotion while separating it sharply from reality," (p. 127). Thus, according to Freud, both the creative writer, and the child are evading reality - one through phantasy and the other through play. To cast further shadows on the activity of creative writing, Freud goes on to say, "We may lay it down that a happy person never phantasies, only an unsatisfied one. The motive forces of phantasies are unsatisfied wishes, and every single phantasy is the fulfillment of a wish, a correlation of unsatisfying reality," (p. 129, Vernon, 1970).

For the most part, therefore, the traditional psychoanalytical approach links creativity to pathology, since the two are sometimes present in the same individual. The question unanswered is, do these two contiguous events necessarily indicate cause and effect?

\section{A "Self-Actualizing" Approach to Creativity}

In 1954, Carl Rogers proposed a tentative theory of creativity based on his definition of the creative process as: "The emergence in action of a novel relational product, growing out of the uniqueness of the individual on the one hand, and the materials, events, people, or circumstances of his life on the other," (p. 71, Rogers, 1959). Rogers' conception of the creative process then is contingent also on the finished product, on some observable 
criterion of creativity. He makes the point, however, that he places no value judgments on the "goodness" of the product nor does he make any distinction about the quality or degree of creativity evident in the product. He does, however, make a distinction between "constructive" and "destructive" creativity, a distinction which will be explained shortly.

Rogers described three conditions he saw as being associated with constructive creativity. They were:

1. Openness to experience: extensionality - Rogers described this concept in terms of "permeability of boundaries in concepts, beliefs, perceptions, and hypotheses," (p. 75, Rogers, 1959). This idea was later expressed by J. P. Guilford in terms of "divergent thinking" (searching for material that is only loosely related to what is already known); and by Mednick (1962) in his concept of freedom of associative flow. Rogers uses a different approach to the concept, however, as he defines this ex- . tensionality as the opposite of psychological defensiveness, instead of Guilford and Mednick's interpretation of it as a cognitive ability. Rogers further discussed this openness to experience in terms of constructive vs destructive creativity. That is, openness to one phase of experience makes creativity possible. However, if the openness is only operating in one area, the creative product may be destructive. On the other hand, an openness 
to experience in all or a large number of areas insures that the creative product will be constructive (Rogers, 1959).

2. An internal locus of evaluation - This concept refers to the idea that the value of the creative product is defined in terms of the satisfaction it brings to the individual. External evaluations of the product are secondary and independent of the individual's internal evaluation of his personal creative product (Rogers, 1959).

3. The ability to toy with elements and concepts This idea refers to the "ability to play spontaneously with ideas; colors, shapes, relationships - to juggle elements into impossible juxtapositions, to shape wild hypotheses, to make the given problematic, to express the ridiculous, to translate from one form to another, to transform improbable equivalents," (p. 76, Rogers, 1959). This ability has been considered important by other writers, including Wallach and Kogan (1965). It has been alluded to by many famous individuals including Einstein, Poincare', and Mozart (Wallach and Kogan, 1965). Einstein, for example, discussed "combinatory play" and "associative play" as necessities for ideas and images.

Therefore, when the above three conditions are present, Rogers believed that constructive creativity would occur. With regard to the creative process itself, Rogers declines to describe it, "for by its very nature it is in- 
describable. This is the unknown which we must recognize as unknowable until it occurs," (pp. 76-77, Rogers, 1959). Although he saw the creative process as indescribable, Rogers did note three ideas which coincide with the creative process. They were:

1. The Eureka Feeling - The feeling that "This is it!"

2. The Anxiety of Separateness - The feeling of being alone, of being the first to discover, the only one who has ever been here.

3. The Desire to Communicate - The desire to share one's creation (Rogers, 1959).

Associative Approaches to Creativity

With the associative view of creativity, we move from personality oriented approaches to a cognitive approach; from clinical to experimental methods; and from emphasis on creative products to emphasis on the creative process. S-R psychologists describe the creative process in terms of the building up of links or bonds between stimu$1 i$ and responses. These links or bonds are called associations. Psychologists who subscribe to this view generally agree with the above statement, however, there are differences in the ways in which they approach the study of these associations. Two of these approaches will be described below: Maltzman and the training of originality; 
and, Mednick and the associative hierarchy.

\section{Maltzman}

Maltzman and his collaborators were interested in "original thinking" which they defined as "behavior which occurs relatively infrequently, is uncommon under given conditions, and is relevant to those conditions, " (p. 229, Maltzman, 1960). Maltzman differentiates between creativity and original thinking. According to Maltzman, original thinking refers to behavior, while creativity is defined as the "products of such behavior and the reactions of other members of a society to those products," (p. 229, Maltzman, 1960). This distinction between original thinking and creativity implies that "an individual may be highly original but not creative" (Maltzman, 1960). That is, original thinking may lead to a product which is not considered creative by Maltzman's (1960) definition. Perhaps such a product, a novel, for example, is written but never pub1ished. Or perhaps it is published but is not recognized by "other members of society." Thus, Maltzman (1960) reasoned that although originality is influenced by societal variables, creativity is so influenced to a far greater extent. Therefore the study of originality seems more appropriate for laboratory investigation. As a result of this reasoning, Maltzman and his colleagues became interested in finding ways to foster original thinking. They believed that originality could be promoted through 
positive reinforcement, if the level of original thinking (normally of low frequency) could be raised enough to make reinforcement effective (Maltzman, 1960). Indeed, Maltzman (1960) presented support for this hypothesis. He described a procedure which was consistently found to facilitate originality. "This procedure involves the repeated presentation of a list of stimulus words in a modified free association situation accompanied by instructions to give a different response to each stimulus. Under these conditions the responses became more uncommon. When presented with new stimulus materials Ss receiving such training are reliably more original than the Ss receiving no training," (p. 241, Maltzman, 1960).

\section{Mednick}

Mednick (1962) has advanced an associate theory of creativity which is built on his definition of the creative thinking process as the "forming of associative elements into new combinations which either meet specified requirements or are in some way useful," (p. 221). He suggests that the "more mutually remote the elements of the new combination, the more creative the process of solution," (p. 221, Mednick, 1962). Mednick also distinguishes between originality and creativity, although along different lines from Maltzman. Mednick incorporates a criterion of usefulness into his definition, but makes no reference to reactions of society to the creative product. 
Mednick (1962) has identified. three ways of achieving a creative solution, that is, of combining remote associates. These are:

1. Serendipity, or the contiguous environmental appearance of stimuli which elicit associative elements.

2. Similarity of the associative elements, or of the stimuli eliciting them.

3. Mediation, or the evoking of remote elements through the mediation of elements common to the remote elements.

Mednick (1962) refers to the organization of an individual's associations as an associative hierarchy. This organization influences the probability and speed of attainment of a creative solution. From this idea of an associative hierarchy, he goes on to predict the type of hierarchy which will predispose a person to be able to reach creative solutions. He speaks about the various slopes of individual associative hierarchies. For example, a person who tends to be restricted to stereotyped responses is characterized as having an associative hierarchy with a steep slope. That is, once past the conventional responses to a stimulus, the individual's associative strengths to other words or ideas drops dramatically. The individual whose associative hierarchy is characterized by a rather flat slope, however, is able to go beyond conventional responses to more remote ones. For him, the 
conventional responses may be dominant but not so much so that he is prevented from proceeding from the conventional response to a more remote one. It is predicted that the highly creative person (flat hierarchy) would respond slowly and steadily and emit many responses, while the low creative person (steep hierarchy) would respond at a higher rate but emit fewer responses.

An idea which follows from the above predictions is that "the greater number of associations that an individual has to the requisite elements of a problem, the greater the probability of his reaching a creative solution," (p. 224 , Mednick, 1962).

On the basis of his associational point of view, Mednick (1962) has designed a test of creativity known as the Remote Associations Test (RAT). in this test, creativity is assessed from the number of associations an individual is able to make to any given stimulus word. It is assumed that those highly creative will make a greater number of associations to any stimulus word than will less creative people. The test items consist of sets of three words. Each of the three words in a given set is a statistically infrequent free-association to the same fourth word. The subject's task is to produce the fourth word, which is the mediating link between the three other words. The example given by Mednick (1962) is:

$$
\text { rat blue cottage }
$$


The subject is asked to find a fourth word which could serve as a connective link between these three words. The answer to the example is "cheese." This test has been criticized as being more closely related to convergent than divergent thinking since there is a definite "right" answer to each item. Furthermore, this test is limited by the creativity of its author. Perhaps a more creative subject could find a different mediating link for the above example. His response, however, would be scored incorrect.

In conclusion, we see that creativity has been viewed as a pathological symptom, a result of mental health, and finally, as an ability to form remote associations. In addition to these approaches, various researchers have concentrated on a psychometric approach to creativity. The following willinclude descriptions of their research.

\section{Creativity Tests}

\section{The Guilford Tests}

Toward the end of WWII, psychologists began to attempt to develop instruments for the measurement of creativity. J. P. Guilford has been a major contributor to this emphasis and it was he who provided the impetus for increasing interest in creativity since the 1950's. Guilford's research is based on the premise that "we must look we11 beyond the boundaries of the IQ if we are to fathom the domain of creativity," (p. 448) and the belief that the 
attempt to account for creative talent in terms of high intelligence IQ, has been largely responsible for lack of progress in the understanding of creative people (Guilford, 1950). Guilford, therefore, has directed his attention to measures of the intellect which would tap abilities that are not usually thought to be involved in tests of intelligence (Stein, 1968).

Guiford (1967) has identified two areas of measurement in the general field of creativity. They are the measurement of creative potential and the measurement of creative performance. Creative potential refers to motivational, temperamental, and aptitudinal traits that a person brings to a potentially creative situation, and which predispose him to act creatively. Creative performance refers to the actual products of creative activity. The tests developed by Guilford to measure creative potential are based on his model of the human intellect, and are concerned with assessing cognitive abilities believed to be involved in creative thinking. The first dimension of Guilford's three-dimensional model is concerned with processes or thinking operations carried out. These operations include cognition, memory, divergent and convergent thinking, and evaluation. The second dimension is concerned with the contents to which these operations are applied, i.e., figural, symbolic, semantic, and behavioral. The third dimension is concerned with products 
that can result from the above operations. These include units, classes, relations, systems, transformations, and implications. According to Guilford, any intellectual activity can be viewed as some combination of the 120 abilities contained in this three-dimensional space. According to Guilford (1957), the most obvious indications for creativity lie in the area of divergent thinking. Livergent thinking is distinguished from other operations by the fact that it results in a variety of responses rather than single "correct" response. For example, convergent thinking involves zeroing in on an answer that is rather precisely implied or specified by the nature of the informational givens. Divergent thinking, on the other hand, involves searching for material that is only loosely related to what is already known (Wallach, 1970). It is, of course, possible to arbitrarily define creative thinking as divergent thinking, but it would be incorrect to say that divergent thinking accounts for all the intellectual components of the creative process (Guildford, 1959). Divergent thinking, however, is a prominent part of creative thinking as Guilford sees it. Specific divergent thinking subprocesses have been isolated by Guilford by factoranalytic techniques. These factors are: word fluency, associational fluency, ideational fluency, expressional fluency; spontaneous flexibility, adaptive flexibility; redefinition; originality; and elaboration (Wallach, 1970 ). 
These factors have been correlated with personality characteristics (Stein, 1968).

\section{Fluency}

Fluency of thinking, the quantitative aspect of creativity, has to do with fertility of ideas. This factor of fluency encompasses word, associational, ideational, and expressional fluency.

Word fluency, first reported by Thurstone (1938), is the ability to produce words each containing a specified letter or combination of letters. Drevdahl (1956) found word fluency to be related to creativity in both science and art students.

Associational fluency is best indicated in a test that requires the subject to produce as many synonyms as he can for a given word in a limited time. In contrast to word fluency, associational fluency involves a requirement of meaningfulness for the words given. To make a good score for associational fluency, one must extend his list of synonyms to those that are only tenuously related to the given word. Persons who do well in tests of associational fluency tend to have a stronger need for adventure and they are more tolerant of ambiguity (Guilford, 1949). Fluency in the production of ideas is referred to by Guilford as ideational fluency. In scoring for this factor, quantity is the important consideration; quality need not be considered as 1ong as responses are appropriate. A 
test of this factor may ask subjects to name objects that are hard, white, and edible, or to give uses for a common brick. Ideational fluency probably plays an important role in problem-solving. Many problems require novel solutions, which means creative thinking. Persons high in scores for ideational fluency are inclined to be more impulsive, more ascendent, and more confident and to have a stronger appreciation of creativity. Highly nervous and depressed persons tend to be slightly lower on tasks requiring ideational fluency, but are not handicapped on tasks involving other types of fluency (Guilford, 1959).

Expressional fluency is best measured by a test requiring production of phrases or sentences. The need for rapid juxtaposition of words to meet the requirements of sentence structure seems to be the unique characteristic of tests of this ability. Persons who score higher in tests of expressional fluency are inclined to be more impulsive, to appreciate esthetic expression and to like reflective thinking (Guilford, 1959).

\section{Flexibility}

Guilford hypothesized that creative thinkers are flexible thinkers. They readily desert old ways of thinking and strike out in new directions. This factor of flexibility encompasses two abilities: spontaneous flexibility and adaptive flexibility. 
Spontaneous flexibility is the ability to produce a great variety of ideas, with freedom from inertia or from perseveration. In tests of this factor, the subject shows his freedom to roam about in his thinking even when he is not required to do so. In naming uses for a common brick, for example, he jumps readily from one category of response to another. Rigid thinkers, on the other hand, tend to stay within one or two categories of response (Guilford, 1959).

Adaptive flexibility facilitates the solution of problems. This is shown best in a type of problem that requires a most unusual type of solution. The problem may appear to be solvable by conventional means but these methods will not work. One task that calls for an unusual solution is based on the familiar game involving matchsticks. The subject is given a set of contiguous squares, each side formed by a match. The subject is then told to take away a specific number of matches. With the remaining matches, the subject is asked to form a specified number of squares. He is not told that the squares must be all the same size, but if he adopts this obvious assumption, he cannot solve one or more problems, for the only satisfactory end result is a number of squares that vary in size (Guilford, 1959 ).

\section{Redefinition}

Redefinition is the ability to give up old interpre- 
tations of familiar objects in order to use them or their parts in some new ways. For example, which of the following objects, or their parts, could be best adapted to making a needle: pencil, radish, shoe, fish, or carnation? The correct response is fish since a fish bone seems most readily adaptable to making a needle. Improvising probably reflects redefinition, while functional fixedness prevents it (Guilford, 1959).

\section{Originality}

Unusualness, in a statistical sense, is one principle of measurement of originality. This factor is indicated by tests in which items call for remote associations or relationships, remote either in time or in a logical sense. If examinees list all the consequences they can think of in the event that a new discovery makes eating unnecessary, the number of remote consequences they give indicates originality, whereas the number of obvious consequences indicates ideational fluency. This means it takes a quality criterion to indicate the extent of originality of which a person is capable. Another way of indicating degree of originality in taking tests is the number of responses an examinee can give that are judged as being "clever." Titles given for short story plots, for example, can be rated as "clever" or "not clever." The number of not-clever responses indicates ideational fluency. The number of clever responses indicates originality. 
Possibly originality and adaptive flexibility are the same thing when we are dealing with verbally meaningful material. Both require getting away from the ordinary or conventional in order to make a good score (Guilford, 1959).

\section{Elaboration}

The factor Guilford has identified as elaboration is indicated by a test in which the examinee is given one or two simple lines and told to construct on this foundation a more complex object. The score is determined by the amount of elaboration demonstrated (Guilford, 1959).

One problem with the Guilford tests is that they are not appropriate for children. Most of the verbal tests are too difficult for young children and probably for most adolescents. E. P. Torrance has directed his efforts toward this problem and the result is the Minnesota Tests of Creative Thinking (Torrance, 1962). These tests were designed for use by school teachers and others involved with children in the fourth grade and above. Many of these tests are adaptations of tests developed by Guilford, although Torrance also added new tests of his. own which were also aimed at assessing divergent thinking abilities.

The Torrance Tests

The Torrance test battery involves both verbal and figural materials. The various verbal and figural pro- 
cedures are, as far as possible, all subjected to the same four types of scoring: for ideational fluency, spontaneous flexibility, originality, and elaboration (Wallach, 1970). An important difference emerges here between the Guilford and Torrance tests. Guilford's tests are designed so that each test measures only a single factor, whereas the tests developed by Torrance can each be scored on several independent factors (Goldman, 1967). Thus, Torrance seems to be more concerned with the interaction of various divergent thinking abilities, whereas Guilford has concentrated on one factor at a time.

The Torrance test is comprised of four tasks: figure completion, circles, product improvement, and unusual uses of tin cans. These four tasks were selected by Torrance as those which in combination might yield the greatest amount of information concerning creative growth. Two of the tasks are primarily non-verbal and two are verbal (Torrance, 1962). In the figure completion task, the child is asked to do the following: by adding lines to the figures presented, sketch some interesting pictures or objects. The child is instructed to try and think of some original and interesting objects. The incomplete figure presumably sets up in an individual tensions to complete it in the simplest and easiest way possible. Thus, the subject has to be able to handle his tensions and delay gratification of this impulse in order to produce an original and elaborate set of figures (Torrance, 1962). 
In the circles task, the subject is presented with circles and asked to make as many objects or pictures from the circles as he can. The subject is again instructed to be original and to "try to think of things no one else will think of" (Torrance, 1962).

The product improvement task presents to the subject a sketch of a stuffed toy dog. Subjects are asked to list clever and unusual ways for changing this toy dog so that it would be more fun for children to play with.

The last task requires subjects to list as many interesting uses for a tin can as they can think of. This task is a direct modification of Guilford's Brick Uses Test.

Although Torrance made an important contribution to designing creativity tests for children, still another area of creativity testing was yet to be modified. This is in the area of the context in which tests of creativity would be given. M. A. Wallach and N. Kogan rebelled against the testing atmosphere which prevails in the tests of Guilford and Torrance.

The Wallach and Kogan Tests

Wallach and Kogan began with the same conceptual approach to creativity as Mednick, emphasizing the importance of associative flow and the freedom to entertain wideranging associative possibilities in a playful manner. They defined the creative process in terms of (a) the production 
of associative content that is abundant and unique, and (b) the presence of the associator in a playful, permissive task attitude. The second consideration aimed at describing a psychological state that would maximize the associative production in question and the definition assumed that some criterion of relevance would have to be met by the associates produced (Wallach, 1970).

Wallach and Kogan's procedures for assessing creativity originated in Guilford's work, but two differences emerged. First, rather than embracing the range of abilities tapped in the Guilford research, with their varying degrees of independence from convergent thinking, the indicators used were limited to measuring productivity and uniqueness of ideational associates. Second, Wallach and Kogan procedures were administered in a manner that would maximize the opportunity to generate associates on the subject's part. In contrast to the time limits and testing context prevailing in the work carried out by Guilford and Torrance, Wallach and Kogan procedures are administered without time limits and in a setting structured to convey the impression that the materials are under investigation as potential games rather than constituting tests for evaluating the competence of the subjects. This is done in an attempt to avoid the possible inhibitory implications of a testing atmosphere (Wallach, 1970).

The Wallach and Kogan tests include three verbal and two visual tasks. All procedures are described as games 
and administered individually. to each child under circumstances free from any time pressure. Procedures do not require subjects to respond in writing as all communication by the child is oral. The tests are designated as instances, alternate uses, similarities, pattern meanings, and line meanings. In all of these procedures the subject is given as much time as he wishes for each item. Task performance is evaluated according to uniqueness (any response to a given item that is offered by only one subject in a given sample), and number (the total number of responses given by a subject to a particular item) (Wallach and Kogan, 1965).

In the instances procedure the child is asked to generate possible instances of a class concept that is specified in verbal terms. For example, the child may be asked to name al1 the round things he can think of, or all the things he can think of that move on wheels (Wallach and Kogan, 1965).

The alternate uses procedure asks the child to generate possible uses for a verbally specified object. The child may be asked to think of all the different ways he could use a newspaper (Wallach and Kogan, 1965).

The similarities procedure requires the subject to generate possible similarities between two verbally specified objects. (Wallach and Kogan, 1965).

The pattern meanings task asks the child to think of possible meanings or interpretations for each of a number 
of abstract visual designs.

The final task, line meanings, confronts the child with one or another kind of line and asks the child to generate meanings or interpretations relevant to the form of the line in question (Wallach and Kogan, 1965).

So in the Wallach and Kogan tests traces of Guilford's influence are found together with a conceptual framework of association theory - an interesting combination. In addition, the Wallach and Kogan tests have been removed from the previous similarity of creativity tests to IQ tests by the incorporation of a "free" setting believed to be more conducive to creative thinking. This test was designed to be administered to children from the fourth grade and above. No means of assessing the creative potential of very young children was available. Ward (19.68), in a study of kindergarten-age children found the figural tasks of the Wallach and Kogan test to be inappropriate for use with preschool-age children. The verbal tasks, instances and alternate uses, were substantially intercorrelated, while the patterns task was not significantly related to the other measures. Ward's (1968) results suggest eliminating the figural tasks from tests of creativity designed for use with young children. The Wallach and Kogan verbal tasks have been used successfully by Biller, Singer, and Fullerton (1969), and Singer and whiton (1971) with kindergarten-age children. 
As mentioned earlier, creativity has frequently been discussed in terms of play. Freud compared the creative writer to a child at play. Rogers discussed the ability to play spontaneously with elements and concepts. Wallach and Kogan and Mednick have considered "combinatory play" and "associative play" to be important factors in the creative process. In view of this, an investigation of the relationship between play and creativity seems most appropriate. A review of the literature on creativity and play behavior will follow. 


\section{Creativity and Play Behavior}

The major concern of the studies to be described here can be simply stated in the question, what is the relationship between a child's play behavior and his creative abilities? Interest in the existence of such a relationship is a rather recent development in the creativity literature. Questions have been raised concerning whether or not clues to creative ability can be seen in the quality of a child's play or in the type of play in which a child is most often engraged.

According to Piaget (1962) play can be defined in terms of assimilation and accommodation. Play is seen as a predominance of assimilation. Piaget discussed symbolic assimilation, or make-believe play, as the source of creative imagination (Piaget, 1962). Dansky and Silverman (1973) discussed the processes of distorting and free assimilation as links which associate play with creativity. As the child relaxes his efforts to accommodate reality, he becomes free to engage in free assimilation. One of the abilities involved in creative thinking may be the ability to generate remote associations, a part of free assimilation. Therefore, playful activity may facilitate creative thinking (Dansky and Silverman, 1973).

A review of studies dealing with creativity and play behavior will be discussed below. Nina Lieberman (1965) explored the relationship be- 
tween the quality of a child's play and his divergent thinking abilities. The qualities of playfulness in the behavior of kindergarten children were identified and rated, and then these qualities were related to the divergent thinking factors of ideational fluency, spontaneous flexibility, and originality, as measured by Guilford and Torrance-type measures as well as by the Monroe Language Classification Test. Playfulness was defined in terms of five traits: physical, social, and cognitive spontaneity; manifest joy; and sense of humor. It was hypothesized that divergent thinking ability would vary positively with an increase in playfulness. The results of this study supported the hypothesis that more playful kindergarten children perform better on divergent thinking tasks than do less playful children.

It should be pointed out that in addition to the correlations between playfulness and divergent thinking abilities, findings also revealed significant correlations between mental age (MA) and divergent thinking abilities. MA was also correlated with four out of five of the playfulness traits (the exception being physical spontaneity). Thus, as Singer and Rummo (1973) pointed out, variations in IQ may underlie the Lieberman (1965) findings.

After reanalyzing the Lieberman (1965) findings, Singer and Rummo (1973) examined possible relationships between ideational creativity and playfulness. The reanalysis of Lieberman's data by computation of partial 
correlations between the various creativity measures and the measures of spontaneity, humor, and joy, with MA held constant, reduced all correlations in magnitude (Singer. and Rummo, 1973). Only the correlations between ideational fluency and the spontaneity, humor, and joy variables remain statistically significant. Singer and Rummo (1973) set out to see if Lieberman's (1965) findings could be replicated using intelligence-free creativity measures. The authors were also interested in comparing their findings with kindergarten children to the findings of Wallach and Kogan (1965) with fifth and sixth graders. In the Wallach and Kogan study, comparisons between boys and girls revealed that intelligence accounted for variations in the observed classroom behaviors for the boys, while intelligence, ideational creativity, and the interaction of these two modes of thinking were responsible for differences among the girls. Singer and Rummo (1973) stated that if different findings emerged in a younger sample, this would suggest a closer look at the impact of school and societal value systems. The authors used Wallach and Kogan creativity measures, since these measures have been found to be independent of IQ in kindergarten children (Biller, Singer, and Fullerton, 1969; Ward, 1968). The authors also derived 15 teacher-rated scales which reflect behavioral attributes similar to those studied by Wallach and Kogan (1965) and Lieberman (1965). Findings revealed that: 
(1) High creative subjects received significantly lower ratings on work orientation (i.e. Automomy, Task Persistence, Acceptance of Responsibility).

(2) On scales measuring playfulness and openness to experience, the results for boys and girls differed. High creative boys were rated significantly higher on Openness and Communicativeness; Curiosity and Novelty-Seeking; $\mathrm{Hu}-$ morous, Playful Attitude; and, Emotional Expressiveness. The results for the girls, however, revealed significant interaction effects on all four Openness to Experience scales. Girls low in both creativity and IQ received especially low ratings, with girls high in both creativity and IQ next lowest.

(3) With regard to Self-Confidence and Participation in Kindergarten Activities, sex differences also emerged. Creative boys were rated higher $(p<.10)$ on SelfConfidence, while Participation in Kindergarten Activities did not vary with either creativity or IQ. interaction effects were again found for girls, with high-high and Low-low subjects rated less self-confident and less involved in classroom activities.

(4) Girls high in both creativity and IQ or low on both measures were seen as less integrated into the peer culture. No relationship between peer relations and creativity was found for boys.

(5) High creative subjects (boys and girls) were rated more tolerant of childishness, better coordinated 
and more graceful, and more prone to respond to frustration with anger and aggression.

In conclusion, with regard to the findings of Singer and Rummo (1973) and Wallach and Kogan (1965), it appears that in boys, the advantages of a highly creative ideational style apparent at ages 5 or 6 disappear by the fifth or sixth grade, where the value of high IQ increases. For girls, however, both high IQ and high creativity appear to be disadvantages at the kindergarten leve1. By the fifth or sixth grade, high-high status seems to have become associated with academic success and low-1ow status with social success (Singer and Rummo, 1973).

Lieberman's (1965) findings with regard to creativityplayfulness relationships were not replicated.

Sutton-Smith (1967) had kindergarten children give alternate uses for four toys which were familiar to them: The children in his sample gave more uses for their preferred familiar toys than for other toys. However, as Dansky and Silveman (1973) pointed out, Sutton-Smith failed to separate the effects of playfulness from those of total exposure to the toys. Dansky and Silverman attempted to separate these effects in their 1973 study. In addition, this study examined the differential outcomes of playful and imitative activity present in Piaget's theory. Dansky and Silverman (1973) used three groups of children aged four to six years $(M=5)$. One group was per- 
mitted to play with a particular set of objects; a second group was asked to engage in an equivalent amount of imitative play with these same objects; a third group was given a "neutral" experience not involving those objects. Subjects were given the Wallach and Kogan alternate uses test in order to obtain a measure of associative fluency. The results of this study provided strong support for the hypothesis that symbolic play facilitates associate fluency. Subjects in the play group scored significantly higher on the measure of associative fluency than subjects in the other two groups. Further, the results supported Piaget's view that imitative behavior is dominated by a tendency to accommodate to reality as opposed to the free combination of ideas thought to be present in assimilation, since imitative play made no contribution to associative fluency.

Finally, in a follow-up study, Dansky and Silverman (1975) explored the question of whether or not playful activity would increase the number of alternate uses that children would be able to give for objects not involved in that activity. Using a play group, an imitative group, and a group which was given an intellectual task (naming an object described by the experimenter), subjects in the play condition gave significantly more standard and nonstandard uses than did the subjects in the imitative or intellectual task conditions. The Dansky and Silverman 
(1973; 1975) findings, therefore, lend strong support to the notion that play creates a set, or attitude, to generate associations to a variety of objects, whether or not those objects are encountered during the play activity. Feitelson and Ross (1973) have investigated whether modeling is an essential prerequisite for the emergence of thematic play and whether or not there is a link between level of thematic play and performance on conventional creativity tests. Thematic play was defined as containing a play theme which is the mainspring of the play activity. Usually thematic play is representational and revolves around a focus. One of the major theses of this study was that thematic play is not a function of maturation. Instead, it was postulated that modeling is necessary for thematic play to occur, even under otherwise ideal play conditions. From this, the authors suggested teaching young children to play thematically as one way to increase their creativity as measured by conventional tests. The results of this study supported the hypothesis that thematic play does not develop spontaneously as the child matures. In addition, low levels of thematic play were not confined to exotic societies or to the economically disadvantáged. The results also supported the hypothesis that modeling is an essential prerequisite for symbolic or thematic play. The content of the tutoring sessions emerged as the important variable in increased levels of 
thematic play, as opposed to materials or the tutoring experience itself. Finally, Feitelson and Ross (1973) succeeded in establishing a causal relationship between the increase in the level of thematic play and improved performance on the Cincinnati Autonomy Test Battery and the Torrance 'Thinking Creatively with Pictures' test. The studies reviewed so far were done in laboratory settings. In fact, studies of children in natural settings, such as the nursery school, are rare. The present study attempted to begin filling this gap in the literature by examining creativity with regard to play behavior as it occurs in the nursery school environment. 


\section{METHODOLOGY}

The purpose of this study was to investigate possible relationships between creativity, as measured by the Wallach and Kogan (1965) verbal tasks and play behavior in the nursery school setting. The items for each task were the same as those used by Biller, Singer, and Fullerton (1969) and followed from the research done by Ward (1968).

It was hypothesized that children who achieved high scores on the Wallach and Kogan (1965) verbal tasks would differ from low-scoring children with respect to the play activities in which they were most often observed. It was further hypothesized that high-scoring children would spend more time in the housekeeping and kitchen areas of the nursery school than low-scorers. This hypothesis stemmed from the work of Feitelson and Ross (1973) who found a link between creativity test scores and thematic play. In the nursery school, the housekeeping and kitchen areas are perceived as being most conducive to thematic, or dramatic, play.

The nursery school environment was observed and ten continuously available areas of play were identified: Housekeeping; (2) Kitchen; (3) Block Corner; (4) Ease1; (5) Book Corner; (6) Blackboard; (7) Science Table; (8) Crayons, Paper, Paste; (9) Puzzles, Beads, Manipulative Equipment; 
and (10) Special Activity. Each of these play opportunities was equally available to each child present in the nursery school and each was available every day. The Special Activity was defined as a relatively novel experience or activity which was equally available to all the children present in the nursery school. Although a Special Activity was available each day, the activities were different each day and involved a wide variety of experiences. Thus, the special Activity was distinguished from the other nine play areas due to its novelty. Activities 1 through 9 were chosen for their stability and availability. Activity 10 was chosen since it was equally available and yet it offered a novel experience for the children. Novelty, originality, and unusualness have been considered important in the creative process and so it was felt that a novel activity would be an appropriate item for study. Therefore, it was hypothesized that children who achieved high scores on the Wallach and Kogan (1965) creativity tasks would be observed more often in the Special Activity than low scorers.

\section{Sample}

The subjects for the present study were 36 (17 male; 19 female) four-year-old children who were enrolled in nursery school at the University of Rhode Island Child Development center for the 1973-1974 school term. Two children served as pilot subjects to enable the experimenter to evaluate the testing procedure and subsequently to 
modify it. One child was excluded because he was not testable. Thus, the final sample consisted of 16 boys and 17 girls aged 4.33 to $5.25(\mathrm{M}=4.72)$.

\section{Materials}

A modification of the Wallach and Kogan Creativity Instrument similar to that used by Biller, Singer, and Fullerton (1969) was used to obtain a measure of creativity for each child. The Wallach and Kogan procedures included two verbal tasks which are designated as Instances and Alternate Uses. Wallach and Kogan (1965) háve reported the split-half reliability of each of their creativity measures according to the Spearman-Brown prophecy formula. All ten of these reliability estimates were .50 or better. Eight of the ten coefficients exceeded .80. These results suggest a high degree of internal consistency for all the procedures.

Although formal validation studies are not available for the Wallach and Kogan procedures, the following indications of validity are available: correlations between the creativity and intelligence measures were extremely low; and the nature of the activities suggest face validity.

In the Instances procedure the subject was asked to generate possible instances of a class concept that was specified in verbal terms. Each child was asked to name all the round things he could think of and all the things he could think of that are red.

The Alternate Uses procedure asked the subject to 
generate possible uses for a verbally specified object. The subject was asked to think of all the different ways he could use a newspaper, a knife, and a coathanger.

Because of the young age of the subjects, each was given objects to hold while being tested. That is, for the Instances procedure, when the child was asked to name things that are red, he was given a piece of red construction paper. When asked to name things that are round, the subject was given two circular pieces of paper made from art paper. In the Alternate Uses procedure the same technique was used by presenting the child with a newspaper, a knife, and a coathanger, respectively.

Other materials included a stopwatch and recording sheets which were used during the observation phases of the study.

\section{Procedure}

The Wallach and Kogan procedures described above were carried out individually with each child under conditions of freedom from time pressure and were described to the children as games. Each child was tested by the same experimenter in a room provided by the University of Rhode Island Child Development Center.

Free play behavior was observed from the observation deck at the Child Development Center by the experimenter. Each of the ten previously discussed play areas were observed over a period of ten days. Each area was observed 
during four one-minute observation periods per day. For each day, therefore, each area was observed once every ten minutes until a total of four one-minute observations were completed for each area. The names of subjects present in each area during each one-minute observation were noted and duly recorded. One-half of the observation periods were completed, and then, the Wallach and Kogan procedures were administered. Following this, the remaining observations were completed.

The creativity tests were scored according to the instructions given by Wallach and Kogan (1965). The raw creativity scores were transformed to $\mathrm{z}$ scores for the group as a whole. The $z$ scores were then split at the median, forming two groups (highs and lows). The means for the high and low groups were 2.1052 and -1.9168 , respectively. In addition, the middle third of the creativity scores were eliminated from the sample for analysis of the upper and lower thirds. The means for the upper and lower thirds were 3.1727 and -2.4681 , respectively. 


\section{RESULTS AND DISCUSSIONS}

\section{Results}

Based on observations of the ten play areas described above, each subject's most preferred activity was determined. Four high creative and four low creative subjects favored two activities equally and these subjects were dropped from analysis. The preferred activities of the remaining subjects are shown in Table 1. Since more than $20 \%$ of the cells had expected frequencies of less than five, chi square could not be computed for this data. However, inspection of the data in Table 1 revealed that for no activity was the difference between high and low creatives less than one. This suggests that the two groups did not differ with respect to the frequency with which they preferred an activity. Analysis of the data, when only the upper and lower thirds of the sample were considered, revealed a chi square value of 3.616 which was not significant.

The hypotheses that high creatives would prefer Activity 1 (Housekeeping) and/or Activity 2 (Kitchen) were explored in Tables 2 and 3, respectively. The Fisher Exact Probability Test with Tocher's Modification (Siegal, 1956) was performed on the data in Tables 2 and 3, yielding a value of .1584 in both cases. Fisher values for the upper and lower thirds of the sample were .0446 and .0554, re- 


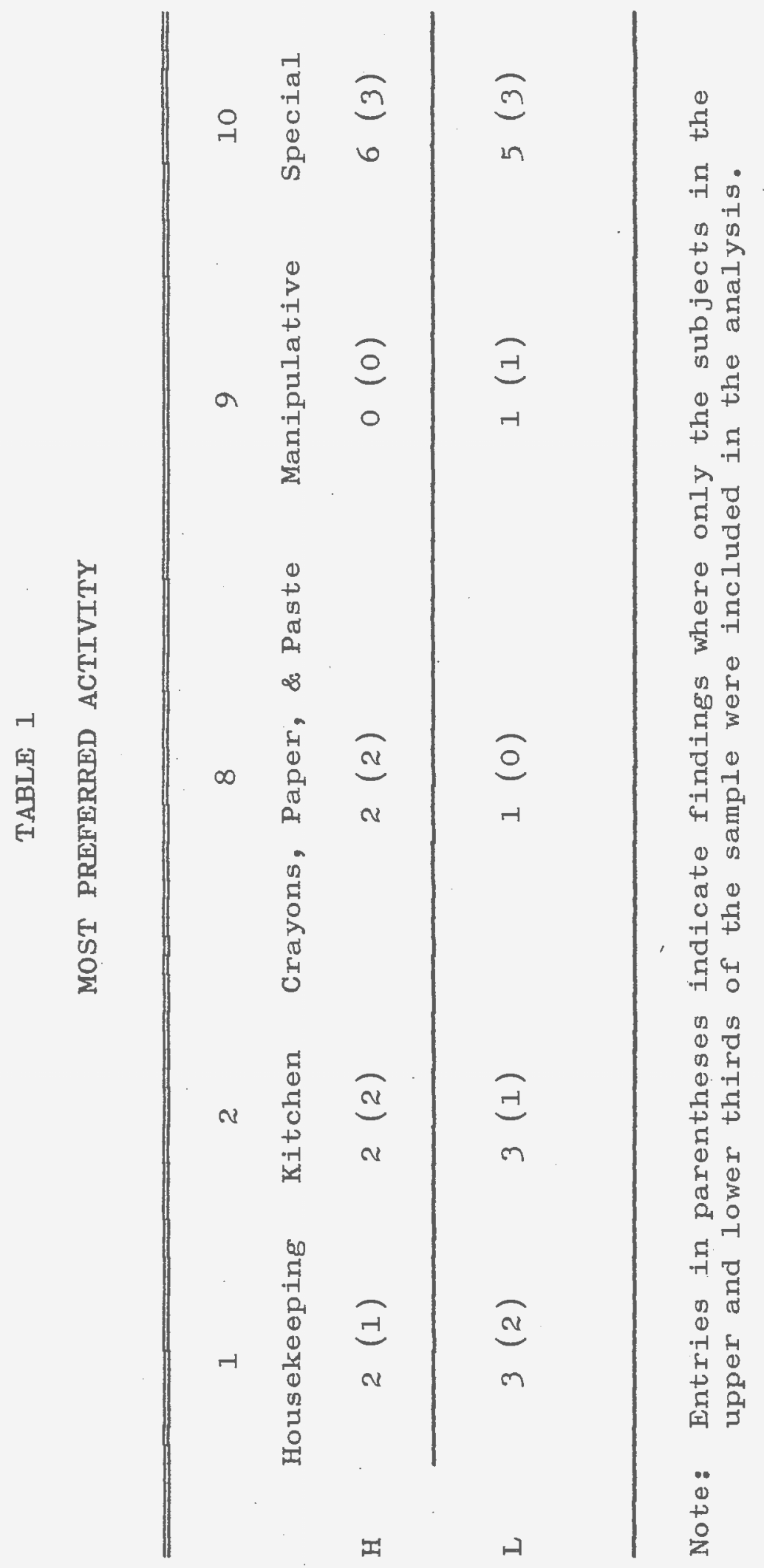




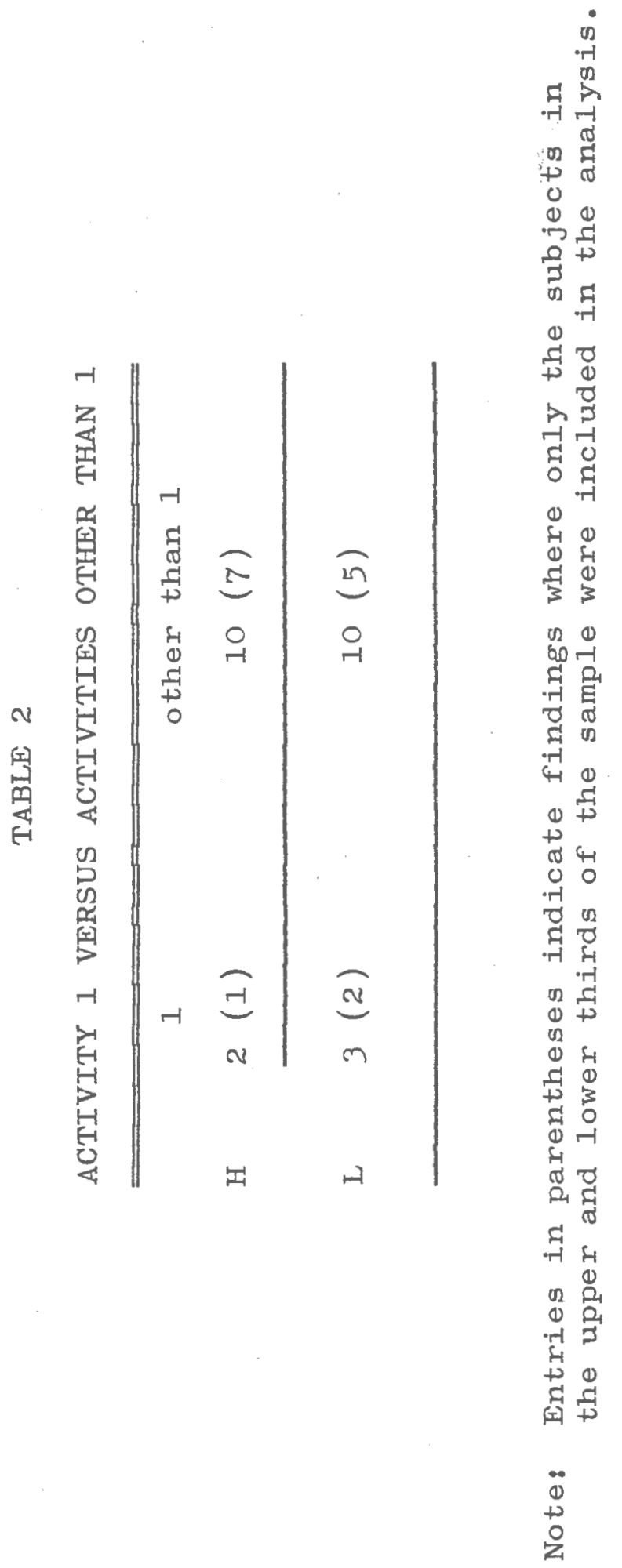




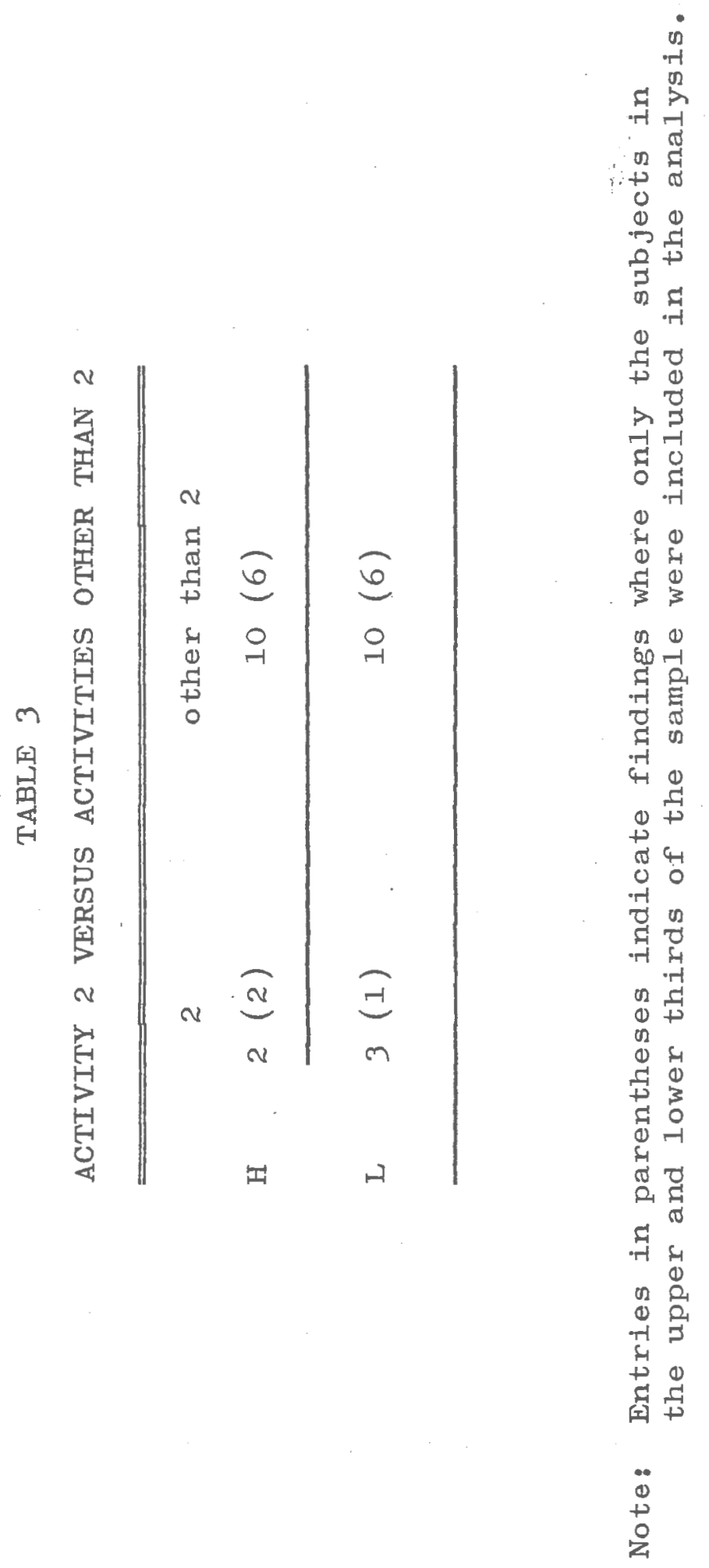


spectively and were not significant. The results were not significant and thus the hypotheses with regard to Activities 1 and 2 were not supported. Eleven of the 24 subjects included in Table 1 preferred Activity 10 (Special Activity) (see Figure 1). The hypothesis that high creatives would prefer Activity 10 was explored in Table 4. The Fisher Exact Probability Test with Tocher's Modification (Siegal, 1956) was performed on the data in Table 4, yielding a value of .031 for the total sample and .6224 for the upper and lower thirds of the sample. The results were not significant and thus the hypothesis with regard to Activity 10 was not supported.

Since so many subjects preferred Activity 10 this may have obscured any differences between the high and low groups on the other activities. Because of this, a post hoc decision was made to determine each subject's most preferred activity if Activity 10 were eliminated from the analysis (see Table 5).

Again cells were too small and so chi square was inappropriate for the data so the data in Table 5 was integrated into Tables 6 and 7 in order to examine the original hypotheses with Activity 10 omitted. Subjects whose preferred activity omitting Activity 10 resulted in a tie were dropped from analysis. Also, subjects for whom Activity 10 and one other activity were tied previously were placed back in this analysis. Table 6 shows no differences between 


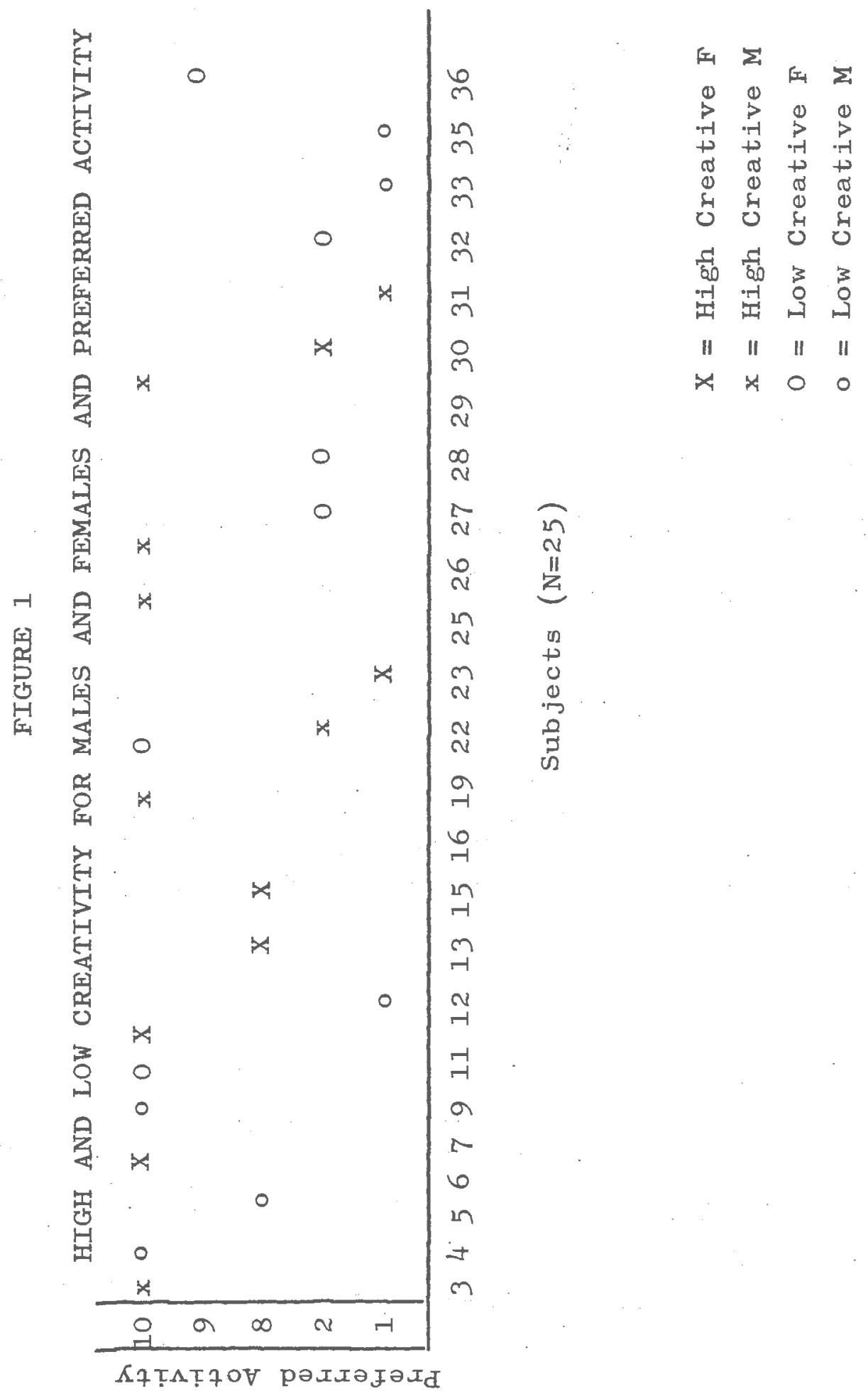




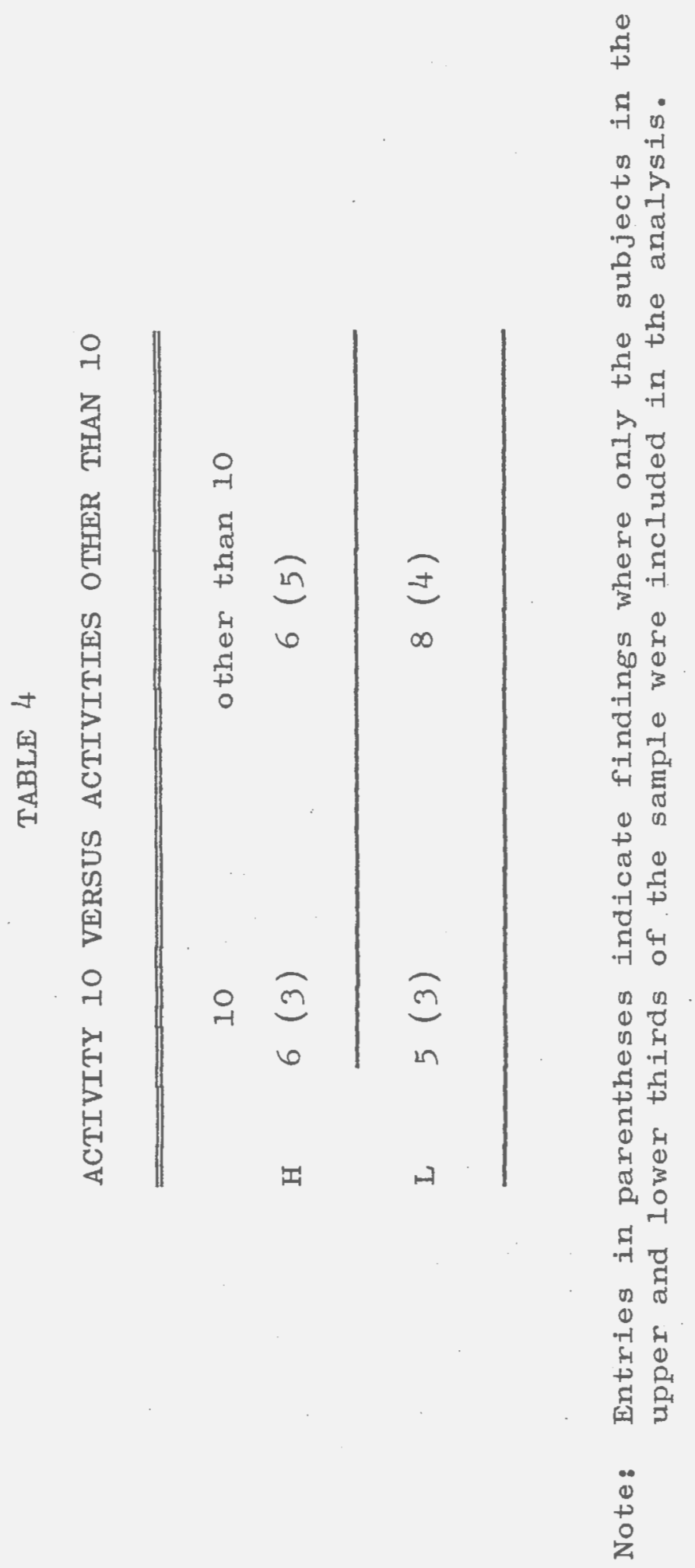




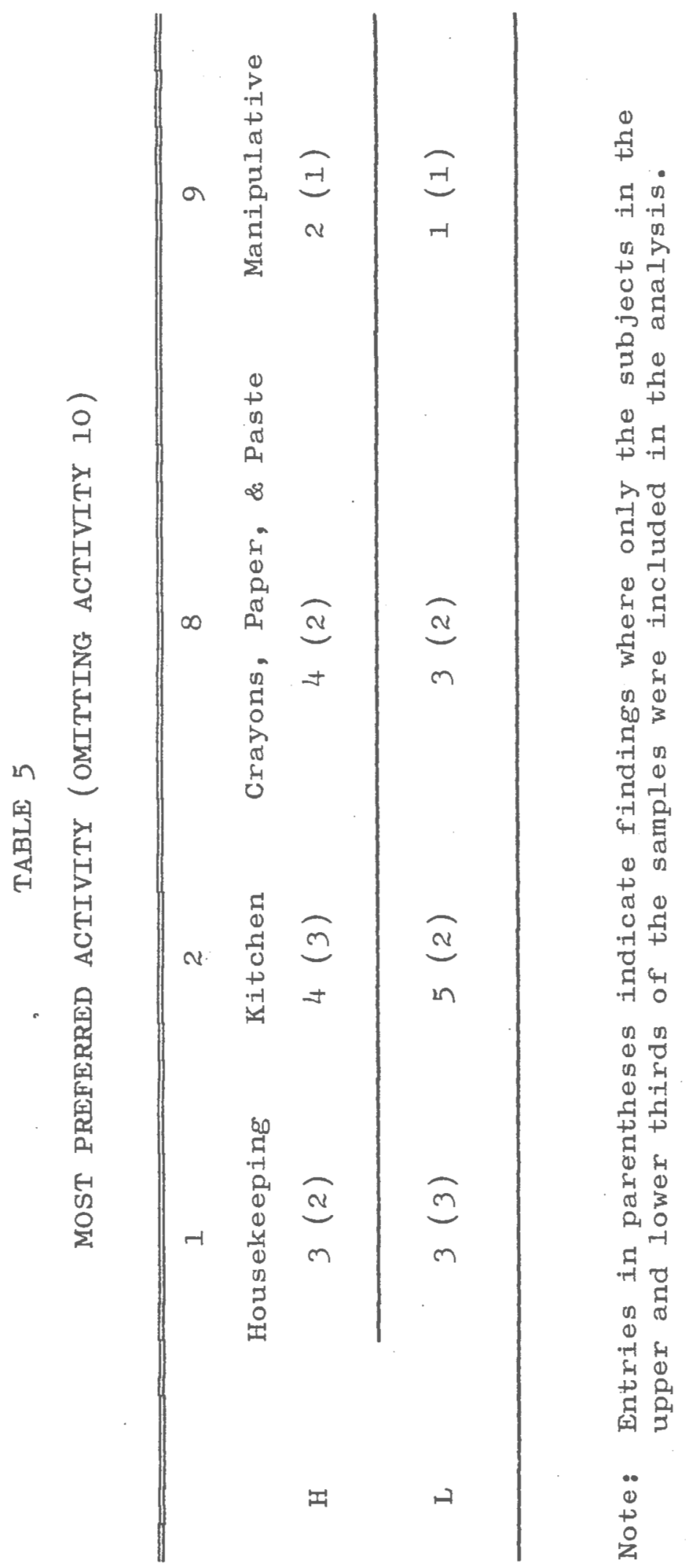


highs and lows with regard to Activity 1 versus activities other than 1 when Activity 10 was omitted. The Fisher Exact Probability Test with Tocher's Modification was performed on the data in Table 6 with regard to the upper and lower thirds of the sample and revealed a value of .5000 which was not significant beyond the .05 level. The Fisher Exact Proability Test with Tocher's Modification (Siegal, 1956) was performed on the data in Table 7, yielding a value of .40032 for the entire sample and a value of .5000 for the upper and lower thirds, neither of which was significant.

In order to investigate possible sex differences on creativity scores, chi square was computed for the data in Table 8. This analysis resulted in a chi square value of .0430 , and was not significant.

The possibility of sex differences with regard to play preference was explored in Table 9. All possible. 2 x 2 analyses of all ten activities were constructed and the results of the Fisher Exact Probability Test for each analysis are reported in Table 9. The results for these analyses were not significant.

In order to investigate possible age differences in creativity, chi square was computed for the data in Table 10. This analysis resulted in a chi square value of .025, and was not statistically significant.

The possibility of age differences with regard to play preference was explored in Table 11. All possible $2 \times 2$ 


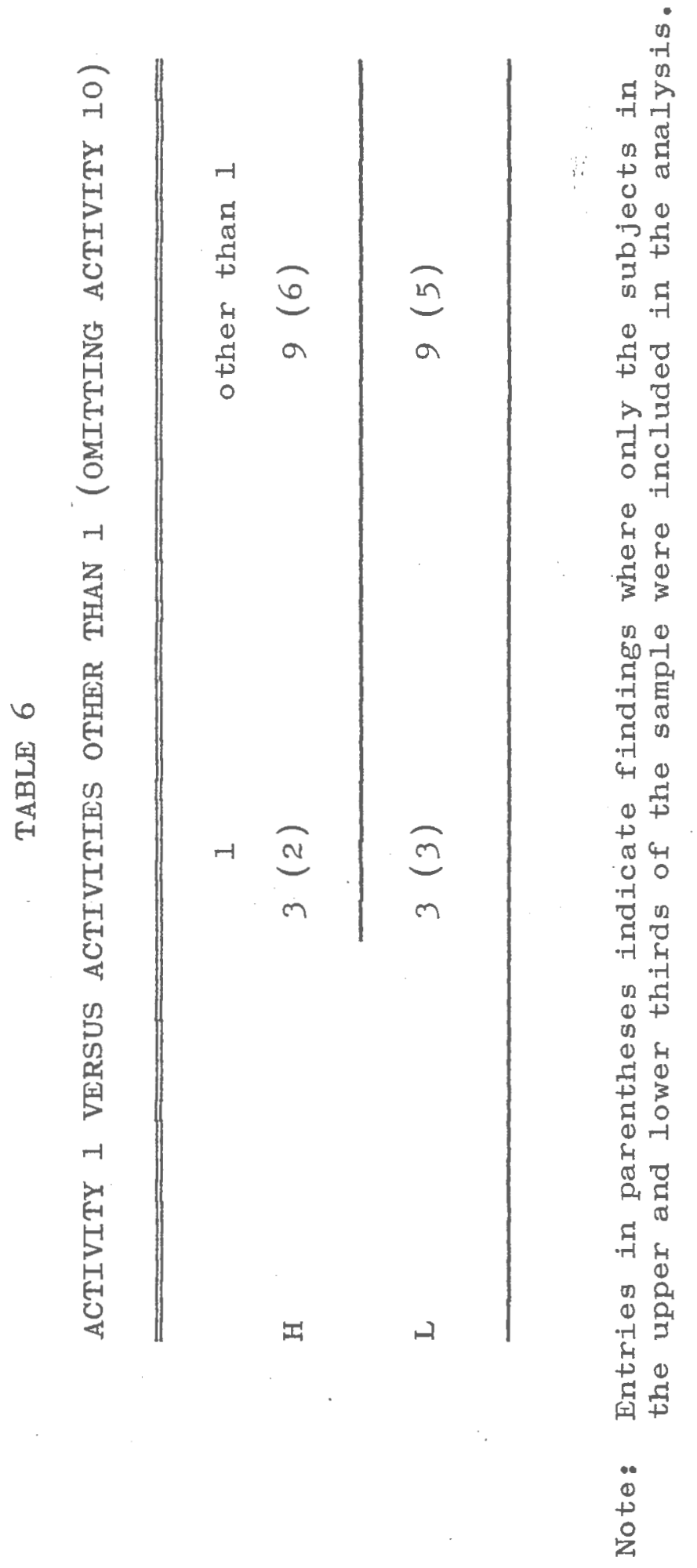




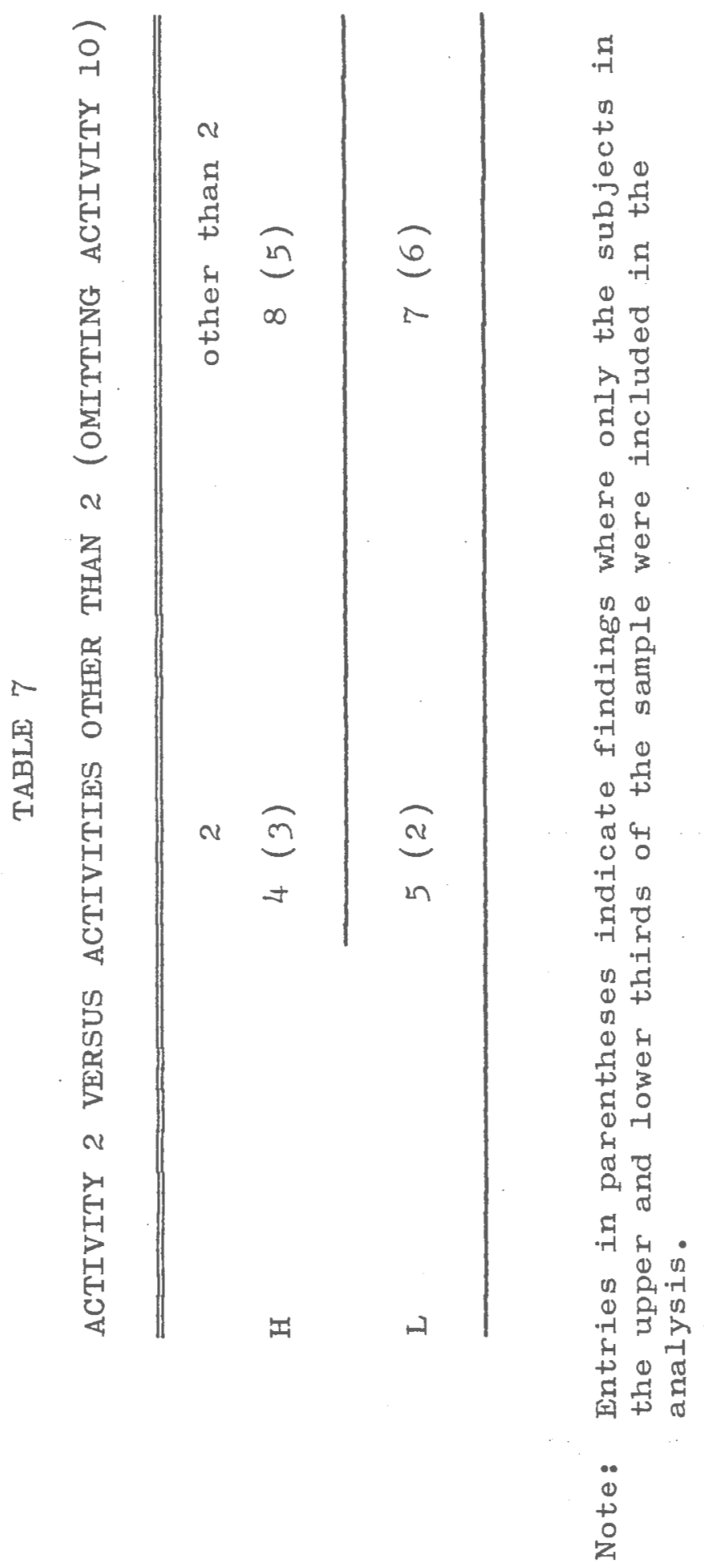




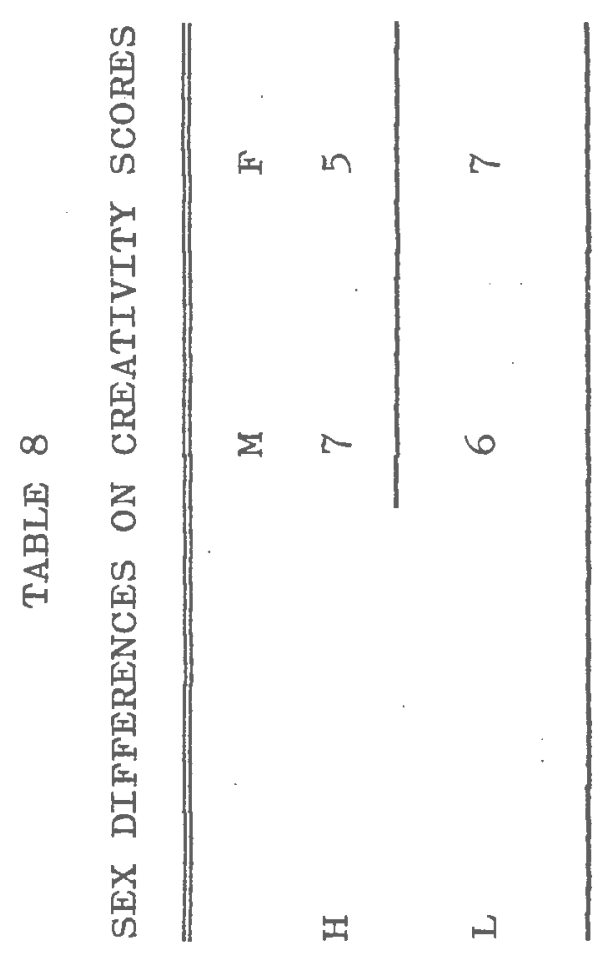




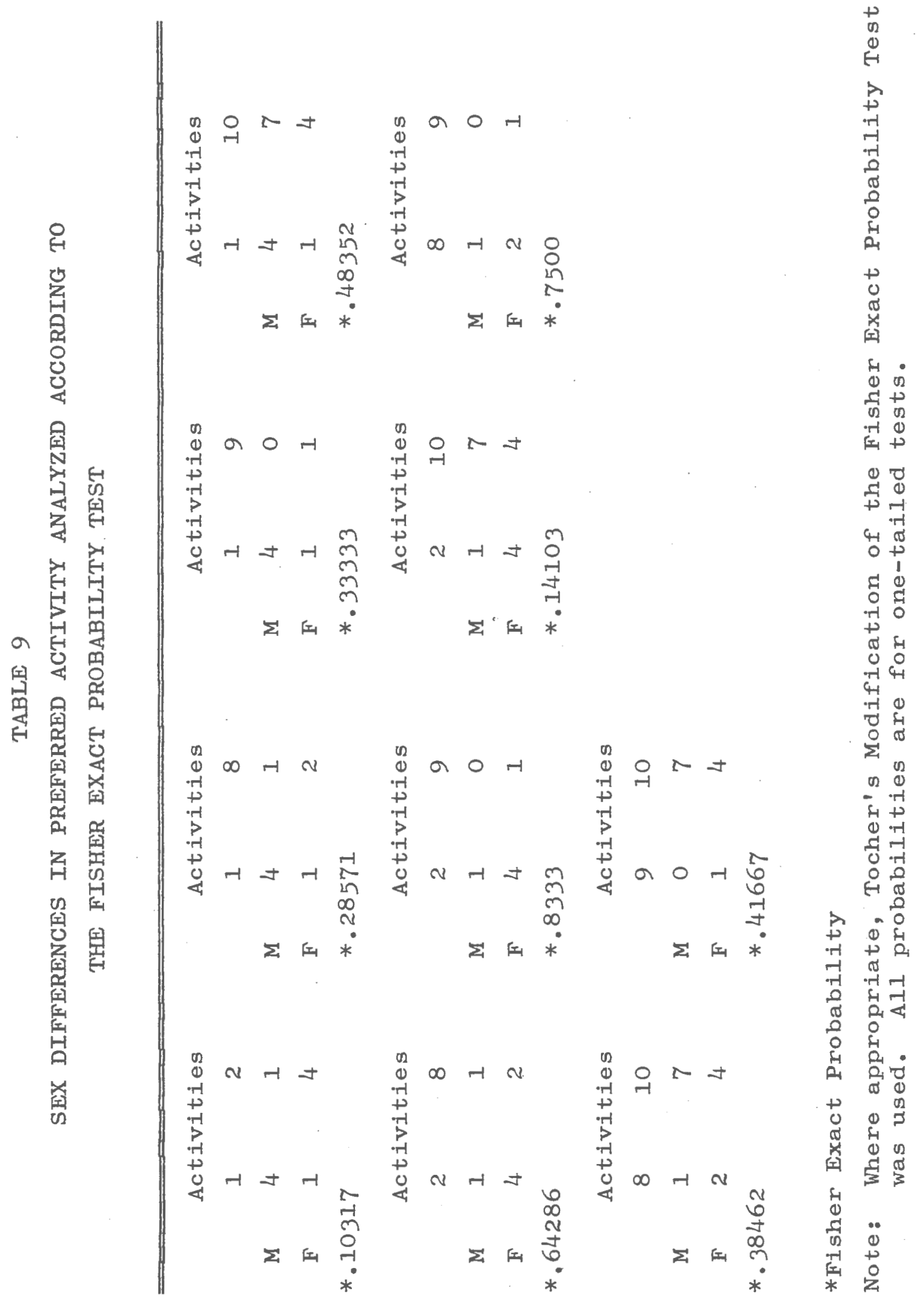




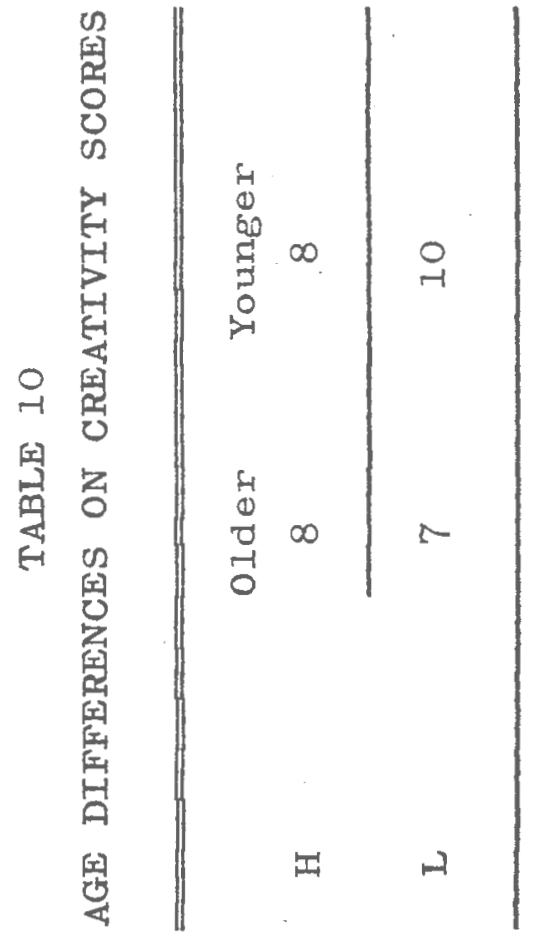




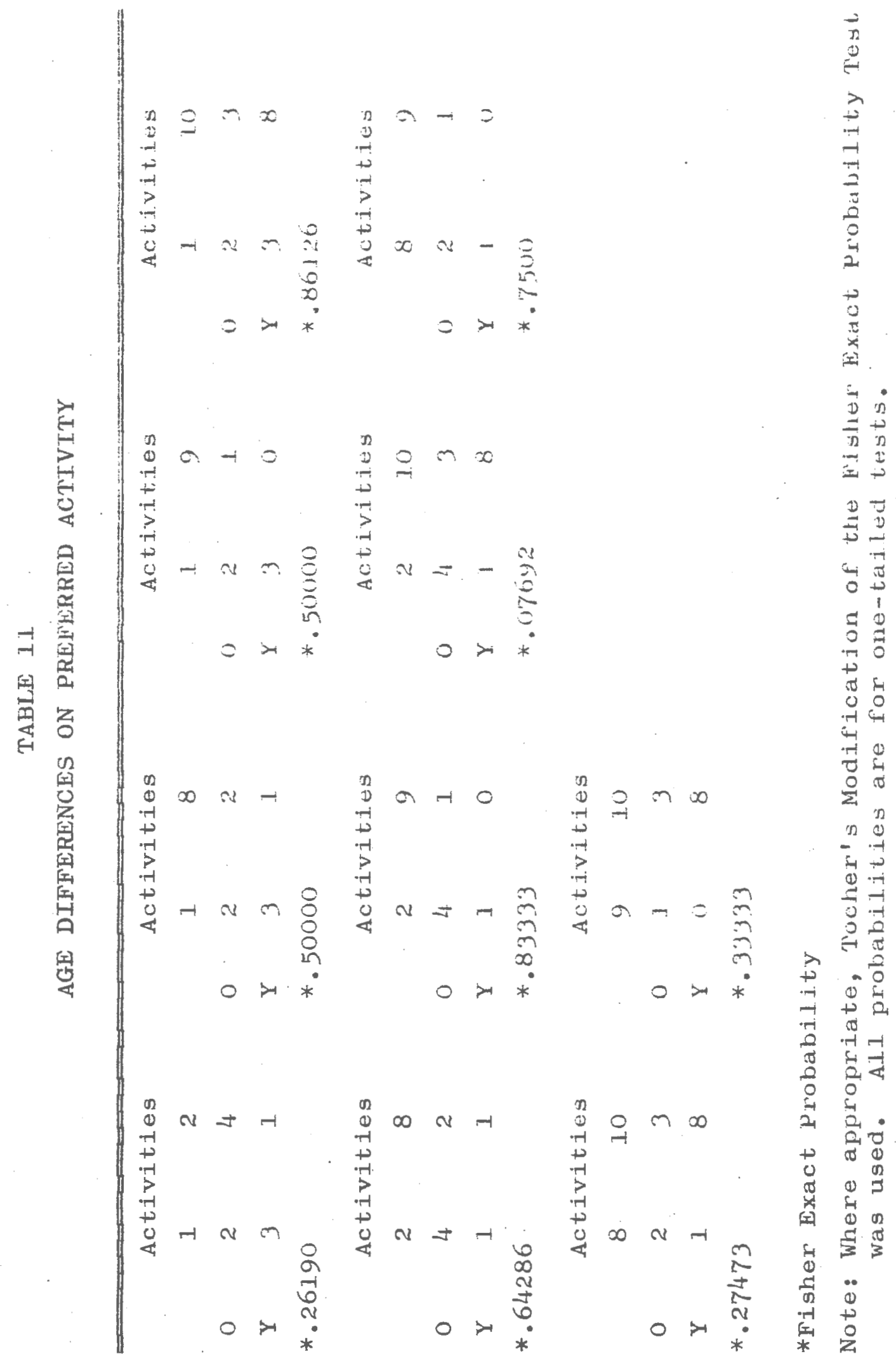


analyses of all ten activities were constructed and the results of the Fisher Exact Probability Test for each analysis are reported in Table 11. The results of these analyses were not statistically significant. 


\section{Discussion}

The results from the present study failed to support the existence of a link between creativity and preferred play areas in this nursery school setting. This could be due to various reasons:

(1) That high creatives do not have different play preferences from low creatives.

(2) That the nursery school does not provide activities which are differentially attractive to highly creative children.

(3) The sample size in this study was too smal1 to detect differences.

(4) The creativity test used may not measure creativity in all children.

(5) High and low creative children may not have been present in this sample.

The first of these alternatives seems more likely since the nursery school which was observed appeared to provide for creative activity. The Housekeeping and Kitchen areas were designed to promote dramatic play. Also, various art media (paint, clay, collage) were available to each child and the children were encouraged by their teachers to manipulate these materials freely, without instruction and without "models".

Due to the small sample size in this study a definitive conclusion concerning these hypotheses is not entirely 
justified. The sample may have been too small to detect differences. Other factors must also be considered in an attempt to discover the implications of these results.

Creativity scores for the Wallach and Kogan type tests are not standardized. The classification of scores depends on the distribution of scores within a given sample. For example, the originality of a response is determined by whether or not that response was given by more than one subject in a given sample. Characteristics of a given sample may therefore be very important. Since norms for the performance of 4-year-olds on these measures are not available, it is impossible to determine whether or not the scores in the present sample include a sufficient number of "high" and "low" creative children to provide an adequate test of the major hypotheses. It may be that the present sample was too homogeneous to reveal large differences in creativity scores and thus, larger and more diverse samples are indicated for future studies so that clear differences can be revealed. Other factors of importance are inherent in the setting in which this study was done. As in most studies using naturalistic settings, many variables enter the study which cannot be adequately controlled. For example, in the nursery school, the activities in which children participate may be influenced by many variables. A favorite teacher may be involved in an activity and the child may choose to participate in this activity in order to be near her. Parents may expect 
"finished products" from their children and thus, a child may paint a picture, make a collage, or engage in other activities in order to be able to present such a finished product at the end of the nursery school day, avoiding activities which are involved in process rather than product.

Another important variable may be friendship patterns among the children in the nursery school. One of the goals of the teachers for the children in the school which was observed was increased social skills and social interaction. Again, children may participate in an activity because their friends are doing so or because teachers may encourage the child to interact, thus leading him to an activity where other children are involved.

Creativity may be important in determining a child's play preferences, but variables, such as those mentioned previously, may also be acting on the child in such a way as to obscure a clear relationship between creativity and play preference. The possible presence of uncontrolled variables in the present study could therefore explain why many laboratory studies have been able to detect significant trends in the relationship between creativity scores and play behavior and this study was not able to do so. In addition, the effects of creativity on play preferences may be so subtle that they can only be detected in a controlled laboratory setting.

The finding that almost half of the subjects in this 
study preferred the special Activity suggests that novelty is a very important factor for four and five-year-old children in the nursery school. The attraction that novelty had for these children, in both the high and low creativity groups, suggests that the novelty effect may have obscured other factors which may also influence play preference. An important aspect of novelty, which was not explored in the present study, may be the extent of the child's involvement in the novel activity. It may be that highly creative children explore a novel experience more fully than do less creative children.

Another problem in the present study concerns the lack of a measure of the quality of dramatic play. In addition to observing areas of the nursery school which supposedly encourage dramatic play, useful additional information might be gained from the observation of dramatic play itself. In this way, some judgment of the depth of involvement in dramatic play could be made and in addition, information could be gained in observing in what parts of the nursery school dramatic play actually occurs. 


\section{SUMMARY}

The purpose of the present study was to investigate possible relationships between creativity, as measured by the Wallach and Kogan (1965) verbal creativity tasks, and play preferences in the nursery school. It was hypothesized that children who achieved high creativity scores would differ from low-scoring children with respect to the play activities in the nursery school in which they were most often observed. It was further hypothesized that high scoring children would be more attracted to the housekeeping and kitchen areas of the nursery school than low-scorers. This hypothesis stemmed from the research of Feitelson and Ross (1973) who found a link between creativity scores and thematic play. In the nursery school, the housekeeping and kitchen areas are perceived as being most conducive to thematic play. In addition, novelty, originality, and unusualness have been considered important in the creative process and therefore, it was hypothesized that highly creative children would be more attracted to a novel play activity than low creatives.

Results from this study failed to support the above hypotheses. It was suggested that the effects of creativity on play preferences may be too subtle to be apparent in a naturalistic setting such as the nursery school. Other 
variables (e.g., friendship patterns, teacher preferences, parents' expectations) may have obscured any effects creativity may have had on play behavior.

Novelty was found to be a very attractive factor in play for both high and low creative children in this sample. It was suggested that future studies explore the effects of novelty with regard to creativity in more depth. 


\section{SUGGESTIONS FOR FUTURE RESEARCH}

In the past, play behavior and its relationship to creativity has been studied primarily in the laboratory context. The present study attempted to study this relationship in a naturalistic setting. Former laboratory studies have concentrated on quality of play whereas the present study gave attention to play preferences. A valuable contribution could be made by future studies through a combination of these two approaches. That is, a study which explored both play preference and the quality and content of play, and which did so within the context of a naturalistic setting, would yield much information about the possible interaction of the level of creativity and play. In addition, future studies would yield more information by employing larger samples and samples which were more diverse than the sample used in the present study.

Another variable which should be investigated in future studies is age. Longitudinal data on changes in levels of creativity and changes in play preferences and interests would provide insight into the creative process and its development.

The results reported in the present study regarding novelty indicate that this may be an important area of investigation for future research in the nursery school. Future 
studies might, for example, include several novel activities in addition to stable ones. It may be that highly creative children may be more willing to explore a greater number of novel situations than children who achieve lower creativity scores. In addition, highly creative children may show a sustained interest in exploring a novel experience, whereas less creative children may show only an initial reaction to novelty.

Another area of interest which could be explored in future studies might be the child's play preferences at home. This information would add insight into the child's play preferences in the nursery school.

In addition, it may be that the key to the relationship between creativity and play behavior does not lie in play preference alone, but also in the more general area of a child's approach to play, regardless of the play activity. 
REFERENCES

Anastasi, A. and Schaefer, E. E. Biographical correlates of artistic and literary creativity in adolescent girls. Journal of Applied Psychology, 1969, 53(4), $267-273$

Biller, H. B., Singer, D. L., and Fullerton, M. Sex-role development and creative potential in kindergartenage boys. Developmenta1 Psychology, 1969, $1(3)$, $291-296$

Dansky, J. L. and Silverman, I. W. Effects of play on associative fluency in preschool-aged children. Developmental Psychology, 1973, 2(1), 38-43. Dansky, J. L. and Silverman, I. W. Play: A general facilitator of associative fluency. Developmental Psychology, 1975, 11(1), 104.

Drevdahl, J. E. Factors of importance for creativity. Journa1 of C1inica1 Psychology, 1956, 12, 21-26. Dreyer, A. S. and Wells, M. B. Parent values, parental control, and creativity in young children. Journal of Marriage and the Family, 1966, 28, 83-88.

Feitelson, D. and Ross, G. S. The neglected factor - play. Human Development, 1973, 16, 202-223.

Goldman, R. J. The Minnesota tests of creative thinking. In R. L. Mooney and T. A. Razik (Eds.), Explorations in Creativity. New York: Harper \& Row, 1967, 281287 . 
Guilford, J. P. Creativity. American Psychologist, 1950, 2. $444-454$.

Guilford, J. P. Creative abilities in the arts. Psycho1ogical Review, 1957, 64, 110-118.

Guilford, J. P. Traits of creativity. In H. H. Anderson (Ed.), Creativity and its cultivation. New York: Harper, 1959, 142-161.

Guilford, J. P. Measurement of creativity. In R. L. Mooney and T. A. Razik (Eds.), Explorations in creativity. New York: Harper \& Row, 1967, 281-287.

Helson, א. Childhood interest clusters related to creativity in women. Journal of Consulting Psychology, 1965, 29, $252-367$.

Lieberman, J. N. Playfulness and divergent thinking: An investigation of their relationship at the kindergarten 1eve1. The Journa1 of Genetic Psychology, $1965,107,219-224$.

Mackinnon, D. The nature and nurture of creative talent. American Psychologist, 1962, 17, 484-495.

Maltzman, I. On the training of originality. Psychological Review, $1960, \underline{67}(4), 229-242$.

Mednick, S. A. The associative basis of the creative process. Psychologica1 Review, 1962, 69, 220-232.

Piaget, J. Play, dreams, and imitation. New York: Norton, 1962

Razik, T. A. Psychometric measurement of creativity. In R. L. Mooney and T. A. Razik (Eds.), Explorations 
in creativity. New York: Harper \& Row, 1967, 301309 .

Rogers, C. R. Toward a theory of creativity. In H. H. Anderson (Ed.), Creativity and its cultivation. New York: Harper, 1959.

Siegal, S. Nonparametric statistics for the behavioral Sciences. New York: McGraw-Hil1, 1956.

Singer, D. L. and Rummo, J. Ideational creativity and behavioral style in kindergarten-age children. Developmental Psychology, 1973, 8 (2), 154-161.

Stein, M. I. Creativity: In E. F. Borgatta and W. W. Lambert (Eds.), Handbook of personality theory and research (Vol. 1). Chicago: Rand McNally, 1968.

Storr, A. The dynamics of creation. New York: Atheneum, 1972 .

Sutton-Smith, B. The role of play in cognitive development. Young Children, 1967, 22, $361-370$.

Thurstone, L. L. Primary mental abilities. Psychometric Monographs, 1938, 1. Cited by J. P. Guilford, Traits of creativity. In P. E. Vernon (Ed.), Creativity. Middlesex, England: Penguin Books, 1970. Torrance, E. P. Administrative and scoring manual for abbreviated form VII Minnesota tests of creative thinking. Bureau of Educational Research, University of Minnesota, 1962.

Wallach, M. A. Creativity. In P. H. Mussen (Ed.), Carmichaels' manual of child psychology (3rd ed.) 
Wallach, M. A. and Kogan, N. Modes of thinking in young children. New York: Holt, Rinehart, \& Winston, 1965.

Ward, W. C. Creativity in young children. Child Development, $1968,29,737-754$. 
APPENDIX A

EXAMPLES OF NOVEL ACTIVITIES 
APPENDIX A

Making ice cream.

String painting.

Sand painting and chalk.

Re-cycling newspaper into cardboard.

Making bird feeders using peanut butter, bird seed, and pine cones.

Making scrambled eggs.

Mixing colors using eye droppers. 